This is the author's final, peer-reviewed manuscript as accepted for publication. The publisher-formatted version may be available through the publisher's web site or your institution's library.

\title{
Mating disruption of Lasioderma serricorne (Coleoptera: Anobiidae) in stored product habitats using the synthetic pheromone serricornin
}

Rizana M. Mahroof and Thomas W. Phillips

How to cite this manuscript

If you make reference to this version of the manuscript, use the following information:

Mahroof, R. M., \& Phillips, T. W. (2014). Mating disruption of Lasioderma serricorne (Coleoptera: Anobiidae) in stored product habitats using the synthetic pheromone serricornin. Retrieved from http://krex.ksu.edu

\section{Published Version Information}

Citation: Mahroof, R. M., \& Phillips, T. W. (2014). Mating disruption of Lasioderma serricorne (Coleoptera: Anobiidae) in stored product habitats using the synthetic pheromone serricornin. Journal of Applied Entomology, 138(5), 378-386.

Copyright: ( 2013 Blackwell Verlag GmbH

Digital Object Identifier (DOI): doi: 10.1111/jen.12097

Publisher's Link: http://onlinelibrary.wiley.com/doi/10.1111/jen.12097/full

This item was retrieved from the K-State Research Exchange (K-REx), the institutional repository of Kansas State University. K-REx is available at http://krex.ksu.edu 
Running head: Mating disruption of L. serricorne

Journal of Applied Entomology

Address for Correspondence:

Rizana M. Mahroof

Department of Biological and Physical Sciences

South Carolina State University

300 College Street NE

Orangeburg, SC 29117

\title{
Mating Disruption of Lasioderma serricorne (Coleoptera: Anobiidae) in Stored Product Habitats using the Synthetic Pheromone Serricornin
}

\author{
Rizana M. Mahroof ${ }^{*}$ and Thomas W. Phillips ${ }^{2}$ \\ ${ }^{1}$ Department of Biological and Physical Sciences, 300 College Street NE, South Carolina \\ State University, Orangeburg, SC 29117, USA \\ ${ }^{2}$ Department of Entomology, 123 Waters Hall, Kansas State University, Manhattan, \\ KS 66506, USA
}

${ }^{*}$ Corresponding Author:

T.P. : +1 803536 8174; Fax: +1 8035164685

Email: rmahroof@scsu.edu 


\section{Abstract}

Cigarette beetles, Lasioderma serricorne (F.) (Coleoptera: Anobiidae), cause significant damage to the multi-billion dollar food and tobacco industries worldwide each year. A noninsecticidal alternative to manage $L$. serricorne is the application of mating disruption, in which high levels of synthetic sex pheromone are released to create an atmosphere that results in males failing to mate females thereby causing population suppression or extinction. The reported work used synthetic serricornin, the predominant sex pheromone of $L$. serricorne, in mating disruption trials conducted in selected food and feed processing facilities in South Carolina during 2010 and 2011. Mills subjected to mating disruption trials were monitored using oviposition cups filled with larval food and pheromone traps for males that contained monitoring lures. Immediately after deployment of mating disruption dispensers, trap captures declined significantly and indicated a reduction in population levels, i.e. there was "trap shut down". A significant reduction was observed in numbers of adult beetles caught in the traps eight weeks before and eight weeks after treatment in both years. Beetle numbers from pheromone traps in untreated buildings remained at similar levels or increased after the time of mating disruption deployment in treated buildings. The numbers of adults that emerged from oviposition food cups were generally low and varied irregularly in treated and untreated buildings, and were determined to be of little value for assessing treatment effects on reproduction. These initial field studies in the U.S. suggest that release of the synthetic sex pheromone of $L$. serricorne for mating disruption can significantly inhibit proper orientation behavior of male L. serricorne to females and may lead to pest population decline from mating disruption.

Keywords: Cigarette beetle, food-processing, stored-products, stored grain, tobaccoIntroduction 
Lasioderma serricorne (F.) (Coleoptera: Anobiidae) causes significant damage to durable stored commodities of plant and animal origin. L. serricorne is a pervasive pest with an international distribution mainly in tropical, sub-tropical and warm temperate climates (Edde et al. 2012). L. serricorne is a generalist feeder, known to successfully feed, develop and reproduce on a variety of durable commodities including grain-based products, spices, tobacco, dried medicinal herbs, dried meat and dried dairy products (Howe 1957; Bry et al. 1974; Allotey 1988; Jacob 1992; Ashworth 1993; Dimetry et al. 2004; Mahroof and Phillips 2008a; Edde et al. 2012). This serious beetle pest commonly occurs in dry food factories, warehouses, and other dry storages (Powell 1931) and is the target of many pest control and integrated pest management (IPM) programs (Edde et al. 2012). Larval feeding exclusively causes damage and contamination to commodities, as the adults live only one - two weeks, do not feed, and simply disperse, seek mates and oviposition sites before death (Minor 1979).

Female-produced sex pheromones for L. serricorne were identified during the 1970s and 1980s (reviewed in Phillips et al. 2000). The sex pheromones anhydroserricornin (2, 6diethyl-3,5-dimethyl-3, 4-dihydro-2H-pyran), and serricornin (4,6-dimethyl-7-hydroxynonan3-one) elicit a strong attractive response by adult males (Burkholder 1970). Synthetic pheromones have been used in different types of commercial traps since that time for monitoring the presence of L. serricorne (Chuman et al. 1980; Chuman et al. 1985; Faustini 1985). Most, if not all, of the pheromone-baited traps for L. serricorne used routinely in pest monitoring programs are loaded with the single synthetic pheromone, serricornin (Phillips et al. 2000). Sometimes a food odor or kairomone lure is included with pheromone traps that may enhance the beetle's response to the synthetic sex pheromone (Mahroof and Phillips 2008b).

Mating disruption first proved to be successful in controlling cabbage looper moths, Trichoplusia ni (Hubner) (Shorey et al. 1967), and since then has been used widely on a 
number of agricultural and forest insect pests, predominantly for moths (Cardé and Minks 1995). Mating disruption is a pest mitigation method in which levels of synthetic sex pheromone, much higher than those produced normally by females in a population, are released into the atmosphere of an infested area. The high concentration of pheromone saturates the atmosphere; males are no longer able to locate calling females that may be releasing pheromone at relatively lower natural levels. Males purportedly become either physiologically "confused", in that their nervous systems cannot properly interpret the extremely high levels of pheromone and thus do not respond to females, or they engage in behavioral "false trail following", such that they spend a majority of time orienting to the synthetic pheromone dispensers and fail to find females (Cardé and Minks 1995, Witzgall et al. 2010). Regardless of the mechanism, a successful mating disruption treatment should ultimately lead to females going unmated, oviposition of fertile eggs is reduced and the pest population declines to low numbers or goes to extinction.

A recent review on the applications of pheromones for pest management purposes reported mating disruption applied for a small group of moth species, and none for any beetles that use female-produced sex pheromones (Witzgall et al. 2010). The effectiveness of synthetic serricornin as a male attractant and its relatively low-cost commercial availability presented the opportunity to investigate its use for L. serricorne mating disruption. To our knowledge, no field research has been reported for mating disruption to control L. serricorne or any other beetle pest that uses a female-produced sex pheromone. Therefore, the broad objective of the research reported here was to conduct field trials to evaluate the potential for using synthetic serricornin for mating disruption of $L$. serricorne.

\section{Materials and Methods}

\section{Study sites}


A total of five commercial buildings housing grain-related activities within a $60-\mathrm{km}$ radius of the city of Orangeburg, South Carolina, USA were used from 2009 to 2012 as study sites to conduct mating disruption studies with L. serricorne. Four of these buildings were active grain mills or animal feed manufacturing plants that had separate handling and storage areas, while the fifth was used only as a finished feed warehouse. Here we refer to the sites simply as "Mill 1", Mill 2", "Mill 3", "Mill 4" and "Warehouse". Mill 1 was approximately 2,323 $\mathrm{m}^{2}$ in total floor area and about $10 \mathrm{~m}$ tall with five rooms and a basement. A retail store that sold animal feed and other agricultural supplies was attached to the north side of Mill 1. Mill 2 was about $1,951 \mathrm{~m}^{2}$ in floor area on each of three floor levels and had four rooms in total. We began monitoring adult population of $L$. serricorne at both Mill 1 and Mill 2 in October and November 2009, respectively.

Mill 3 had a floor area of $1,060 \mathrm{~m}^{2}$ and consisted of a single level that had three different areas that included a warehouse, a retail store and a milling area. A large metal storage bin and two separate warehouses storing agrochemicals and other agricultural products were located at the same site, but not included directly in this study. L. serricorne monitoring in Mill 3 began in May of 2010. Mills 1, 2 and 3 produced pet foods and animal feed.

Mill 4 had both a wheat flour mill and a corn mill situated adjacent to each other and connected to a warehouse. The total floor area of both mills combined was about $4,645 \mathrm{~m}^{2}$ and consisted of five floors and a separate area for bagging. Mill 4 produced food for human consumption and our L. srricorne monitoring began in June of 2010.

The fifth facility was a seed warehouse that stored dried seeds in bulk quantities. This warehouse had 9,290 $\mathrm{m}^{2}$ in floor area, consisted of a single building unit at one level that had truck loading and unloading facilities on the north and south ends of the building and an 
office complex attached to the south side of the facility. L. serricorne monitoring in the warehouse began in April of 2011.

\section{Monitoring L. serricorne males}

L. serricorne populations were monitored in each of the five facilities using traps that had lures releasing synthetic serricornin and a food odor kairomone synergist or co-attractant provided by Trécé Incorporated, Adair, OK, USA. Pheromone was released from a rubber septum and the other lure was a solid tablet infused with the kairomone. Two sticky trap designs were used in the study: a diamond-shaped (in side view) trap referred to as Storgard III and another flat trap known as Thinline; both trap designs were from Trécé Inc. Storgard III traps were hung at eye-level at both inside and outside of buildings, outside of bins and on fences to catch flying insects, while Thinline traps were inside buildings only, underneath shelves and machinery, or kept on the floor to catch crawling insects. There were 14 locations inside, and two locations outside, each of Mills 1, 2 and 3 selected for trap placement. In Mill 4 there were 18 traps placed inside and two traps placed outside of the facility. The warehouse was the largest facility of all used and it had 25 trap locations inside and three locations outside. Either a Storgard III or Thinline trap was deployed at each trapping point depending on the type of the location. If the location at a given study site had machines and shelves a Thinline trap was used, and if there was a suitable place to hang a trap at eye level then a Storgard III was used.

All study sites were monitored for adult L. serricorne populations throughout the entire study. Mills were visited monthly at least 2 weeks before any mating disruption application was begun to check traps and record the number of beetles. Captured beetles were counted and removed during each visit. Traps and lures were replaced every three 
months, except for the cases of excessively dusty areas or when traps were saturated with insect catches, at which times replacement was done more frequently.

\section{Monitoring $L$. serricorne oviposition}

To evaluate the effect of reduced mating of females and as a consequence overall reduced reproduction in females due to mating disruption, we attempted to monitor female activity at all experimental sites during the course of these studies. Although attractants for females have been studied (e.g. Mahroof and Phillips 2008b; Fardisi and Mason 2013), we were unable to develop a method to attract or confine females in experimental sites and surgically examine them for insemination. We then decided to look at population-wide oviposition by female L. serricorne over time by deploying host-baited oviposition monitors. Oviposition cups were deployed in specific locations around each facility. These oviposition cups were plastic disposable drinking cups $(9 \mathrm{~cm}$ top diameter $\mathrm{x} 12 \mathrm{~cm}$ in height with white interior and red exterior, Solo Cup Co., Lake Forest, IL USA) that were filled with about $40 \mathrm{~g}$ of dried dog food that served as the oviposition medium for females. These cups were covered with a 5-mm steel hardware cloth screen to prevent contamination by vertebrate pests, but with an adequate space to allow $L$. serricorne females access to the medium for oviposition. The number of oviposition cups deployed in each facility varied depending on the size of the facility and ranged from 6-18 food cups. These cups were deployed at all sites prior and post mating disruption trials, they were replaced bi-weekly and were returned to the laboratory for incubation. The contents of each oviposition cup was transferred to a 300-ml canning jar in the laboratory and placed in an environmental chamber at $28^{\circ} \mathrm{C}, 60 \% \mathrm{RH}$ and $12: 12$ (L:D) photoperiod until adult emergence. Once adults emerged the contents of the oviposition cups were thoroughly examined visually and under a microscope to verify their identity as $L$. serricorne. The total number of adult beetles emerged from each cup was counted and recorded. 


\section{Mating disruption experiments}

Mating disruption should result in reduced reproduction and ultimately a numerical decrease or local extinction of the target pest population. Assessing reproductive levels of $L$.

serricorne populations in the field can be challenging. Preliminary studies determined that checking for spermataphores in trapped or tethered sentinel female beetles would not be effective or practical. For this work we decided to asses any changes that might occur in numbers of males caught in pheromone-baited traps, as well as the level of L. serricorne progeny resulting from food cups, before and after application of mating disruption in treated buildings and in untreated control buildings. Field experiments were conducted during 2010 and 2011 in the current studies. Mill 1 and Mill 2 were treated while Mill 3 and Mill 4 served as untreated control facilities in 2010. In 2011, Mill 1, Mill 2 and the Warehouse were treated with mating disruption, while Mills 3 and 4 were again maintained as untreated controls. The design and the composition of pheromone dispensing devices used for mating disruption in the two years varied slightly. In 2010, synthetic sex pheromone was impregnated into a square black plastic block $(2.5 \mathrm{~cm} \mathrm{X} 2.5 \mathrm{~cm} \mathrm{X} 0.5 \mathrm{~cm}$ thick) of an unknown polymer composition. The block had a hole in one corner to insert a metal wire for hanging. In 2011, pheromone was impregnated into a thin rectangular black plastic block (5 $\mathrm{cm}$ X $2 \mathrm{~cm}$ X $0.15 \mathrm{~cm}$ thick) that was hung using a metal wire. Each of the pheromoneloaded designs released synthetic serricornin at a rate of approximately $1.0 \mathrm{mg} /$ day for up to eight weeks. About $90.54 \pm 0.26 \mathrm{mg}(n=20)$ pheromone was loaded in each plastic block that had 95.0\% pure synthetic serricornin (Bedoukian Research, Inc., Danbury, CT, USA; BRI product \# P5500-95). These mating disruption dispensers were provided by Trécé Incorporate, Adair, OK. Pheromone release devices were deployed at all treated sites in midsummer at a spacing density of 1 device per $23.2 \mathrm{~m}^{2}$ floor area. Beetle monitoring activities continued in treated and control facilities after deploying mating disruption devices. 


\section{Statistical analysis}

Beetle counts in traps were transformed to square root $(x+1)$ due to the presence of many zero-counts prior to statistical analysis. Pheromone trap data were analyzed separately from food cup emergence data. Data collected two weeks prior to treatment and two weeks after treatment were compared statistically to evaluate significant effects of mating disruption. Similarly, beetle captures eight weeks before and eight weeks after treatment were also compared. Time periods of two and eight weeks were selected as measures for short-term and long-term treatment effects. Initial analysis showed that Mill 1 and 2 were not significantly different from each other thus count data from Mill 1 and 2 were analyzed together. Data from other facilities were analyzed independently. Data from Mill 1 and Mill 2 were subjected to two-way ANOVA using the GLM procedure of SAS (SAS Institute 2003) using time (before and after) and years being considered as treatment effects.

Differences between means were determined by Tukey's multiple comparison test at $\alpha=$ 0.05. Significant differences at two and eight weeks before and after mating disruption treatment in the Warehouse were determined by independent t-tests (PROC T-TEST) at $\alpha=$ 0.05 level. Differences at two and eight weeks before and after mating disruption treatment in the untreated control facilities were also determined by independent t-tests (PROC TTEST) at $\alpha=0.05$ level using time (before and after) and years being considered as treatment effects. Untransformed data are reported below.

\section{Results}

\section{Effect of mating disruption measured by pheromone traps}

Monitoring of L. serricorne adult males using traps in Mill 1 showed a relatively high population when traps were first deployed on November 2009 (mean of 28.6 beetles per trap), and that beetle numbers declined during the winter months to 0 beetles per trap in January 
and February. L. serricorne population increased rapidly after May and in July 2010 the total number of $L$. serricorne recorded in traps was highest with an average of $24.0 \pm 12.7$ (SE) beetles per trap in two weeks ending July 14. The first mating disruption treatment was deployed in Mill 1 when the trap catches were highest on July 14. Soon after there was an immediate and substantial decrease in weekly trap captures. However, two-way ANOVA showed no significant differences $(\mathrm{F}=1.08 ;$ d.f. $=1,3 ; \mathrm{P}=0.30)$ for the mean number of male beetles caught in traps for two weeks before and two weeks after mating disruption treatment in Mill 1 during 2010 (Fig. 1). Subsequently, the number of male beetles captured in traps decreased gradually and remained low in the following months. When we analyzed the data over a longer period of monitoring in the same year, a significant reduction $(\mathrm{F}=$ 8.17 ;.f. $=1,3 ; \mathrm{P}=0.006)$ was observed in trap counts for the eight weeks before compared to eight weeks after mating disruption treatment (Fig. 2). Of the untreated control facilities in 2010, Mill 3 had average trap catches of 1.0 and 4.9 beetles per trap for two weeks before and two weeks after, respectively, and means of 4.5 and 9.4 for the eight weeks before and after, respectively, compared to when mating disruption was deployed in treated buildings. These mean trap counts before and after treatment were not significantly different for either the twoweek or eight-week periods (independent t-test, $\mathrm{P}>0.05$ ). The $L$. serricorne population was apparently larger in untreated Mill 4, with means of 2.1 and 9.6 beetles per trap for two weeks before and two weeks after, respectively, and means of 16.1 and 13.4 for the eight weeks before and after, respectively, compared to when mating disruption was deployed in treated buildings. Analysis of the two-week data revealed a significant increase in Mill 4 after other buildings were treated (t-test, $\mathrm{P}<0.05$ ), but no significant difference for comparison of the eight-week data.

L. serricorne trapping data from Mills 1 and 2 showed the overall population levels in the summer of 2011 were lower than in 2010. ANOVA showed that the mean number of 
male beetles captured in traps in 2011 significantly decreased $(F=4.67 ;$ d.f. $=1,3 ; P=0.03$;

Fig. 3) two weeks after mating disruption treatment compared to two weeks prior to treatment for both Mills 1 and 2. Comparison of the same two mills for the eight weeks prior to mating disruption vs. the eight week following treatment were also statistically significant $(\mathrm{F}=6.69$; d.f. $=1,3 ; \mathrm{P}=0.01 ;$ Fig. 4). Treatment of the Warehouse in 2011 found that male beetles captured in traps two weeks before and two weeks after mating disruption was deployed had mean number of beetles per trap significantly reduced from 27.0 to $3.3(\mathrm{t}=4.47$; d.f. $=24$; P $=0.0002)$. Significant reduction $(\mathrm{t}=3.43$; d.f. $=24 ; \mathrm{P}=0.0023)$ was also observed when beetle captures were compared for eight weeks before and after treatment at the Warehouse (Fig. 5).The untreated control Mill 3 had average trap catches of 0.6 and 0.3 beetles per trap for two weeks before and two weeks after, respectively, mating disruption was deployed in treated buildings in 2011, and there were means of 2.9 and 3.3 for the eight weeks before and after, respectively, mating disruption was deployed in those same treated buildings. These mean trap counts before and after treatment were not significantly different for either the twoweek or eight-week periods (independent t-test, $\mathrm{P}>0.05$ ). For untreated Mill 4 there were means of 1.1 and 0.9 beetles per trap for the two weeks before and the two weeks after, respectively, mating disruption was deployed in the treated buildings, and means of 12.9 and 36.0 for the eight weeks before and after, respectively, mating disruption was deployed in treated buildings. Analysis of the two-week data found no significant increase in Mill 4 beetles in the two weeks immediately after other buildings were treated (t-test, $\mathrm{P}>0.05$ ), but statistical comparison of the eight-week data before and after mating disruption was applied to the treated buildings found a significant increase (t-test, $\mathrm{P}<0.05)$. Traps placed in all outdoor locations caught very few beetles during the entire study and these numbers were not used further in analyses.

\section{L. serricorne progeny from oviposition cups}


In Mill 1 during 2010 we found that in the two week period before deployment of mating disruption dispensers there was an average of 24.1 adult beetles that emerged from food cups. This number decreased to an average of 9.6 and 2.7 beetles for two weeks and eight weeks, respectively after treatment, but no significant differences $(\mathrm{F}=0.22$; d.f. $=3,28 ; \mathrm{P}=0.6)$ were found between emergence numbers at these two time period. When Mill 2 was subjected to mating disruption in 2010 the number of beetles emerged from food cups also was reduced from 3.2 at two weeks prior to treatment to 1.1 and 1.2 beetles per cup at two weeks and eight weeks, respectively after the treatment. Analysis of Mill 2 emergence data found no significant differences $(\mathrm{F}=0.18$; d.f. $=3,26 ; \mathrm{P}=0.6)$ for any comparisons of $L$. serricorne emerged before and after the mating disruption treatment. Progeny from food cups in the untreated Mill 3 reflected low numbers overall, with an average progeny count of 3.5 two weeks before and 1.3 two weeks after set-up of mating disruption in the treated buildings (eight week data were not available). Mill 4 had a similarly low beetle population, with means of 0.5 beetles emerging two weeks before and averages of 1.3 and 0.4 beetles emerging two weeks and eight weeks, respectively after Mills 1 and 2 were treated. There were no statistical difference (ANOVA, $\mathrm{P}>0.05$ ) between any pre-treatment and posttreatment numbers for either untreated mill in 2010.

In 2011 the numbers of $L$. serricorne emerging from food cups in Mill 1 were 1.3 beetles per cup two weeks prior to treatment, and 0.9 and 0.5 beetles per cup at two weeks and 8 weeks, respectively, after treatment. The emergence in Mill 2 was 0.1 beetles per cup at two weeks before mating disruption and 0.3 and 0.9 at two weeks and 8 weeks, respectively after treatment. In the warehouse, which was treated for the first time in 2011 , there was an average of 1.1 beetles emerging from food cups in the two weeks preceding mating disruption, and 1.3 and 1.1 at two weeks and eight weeks, respectively after treatment. None of the before and after treatment comparisons were significantly different for treated 
buildings in 2011 (ANOVA, P>0.05). Emergence of beetles from food cups in untreated buildings was low. Mill 3 had 0.0 beetles emerging cups two weeks before treatment and an average of 1.3 and 2.2 at two weeks and eight weeks, respectively, after treatment. For untreated Mill 4 the values were 0.5 beetles per cup at two weeks prior to treatment and 0.4 and 4.3 beetles per cup at two weeks and eight weeks, respectively after other buildings were treated. There were no statistical difference (ANOVA, $\mathrm{P}>0.05$ ) between pre-treatment and post-treatment numbers for any of the treated or untreated buildings in 2011.

\section{Discussion}

Data presented here provide the first evidence to suggest that a synthetic sex pheromone can be used to substantially affect the flight orientation behavior of male $L$. serricorne with potential for population reduction via mating disruption. In all treated facilities there was an immediate "trap shut-down" after mating disruption started, in which number of beetles captured in traps with synthetic serricornin dropped considerably after deployment of mating disruption and low trap capture was sustained for several weeks. The compelling experimental results that support an effect on male behavior caused by a high release of synthetic pheromone are that male response was significantly reduced in treated buildings (Figs 2, 3, 4 and 5) while at the same time males in untreated control buildings had no significant drop in flight response to pheromone but had sustained or increased responses in the time after the other buildings were treated. The reduced response of males to synthetic female sex pheromone suggests male beetles may also respond less to natural pheromone and thus be less able to locate female L. serricorne than in untreated buildings. Experiments by Weihman and Liburd (2006) showed complete "trap shut-down" effects for grape root borer males when mating disruption was carried out using twist-tie pheromone treatments. A "trap shut-down" was also recorded for grape root borer immediately after vineyards were saturated with synthetic pheromone (Webb and Mortensen 1990). The levels of trap- 
shutdown achieved in this current study at all treated facilities for both years suggest that males may not have been able to orient to the female pheromone source and therefore a reduction of mating could occur to some extent.

Sustained reduction in number of male beetles caught in traps in the subsequent months following the mating disruption treatment suggests that mating might have been disrupted or delayed enough in treated facilities during both years to cause an impact on reproduction. We did not observe a complete "trap shut-down" to zero males in any treated building, although numbers of beetles caught in traps after treatment were significantly reduced. It is possible that some mating may still have occurred at low levels under mating disruption with high synthetic pheromone, and some females continued to reproduce with sperm carried from mating that occurred before the experimental treatments began. Such carry-over mating may have resulted with $L$. serricorne populations being maintained at low levels in all treated facilities through the second year of the study. In addition, gravid females may have been immigrating into facilities or were brought in with infested stocks, thus contributing to the low levels of L. serricorne observed.

Results with beetle progeny emerging from oviposition cups should be a good indicator of overall reproduction within a population because these data should allow an assessment of whether or not females were mated less following the treatment, and are also a general assessment of overall reproductive levels of the beetle population and level of commodity infestation. Food cup data in this study were equivocal and do not support a hypothesis of effective mating disruption because we found no statistically different decreases in reproduction following treatment nor any significant difference in population trends between treated and untreated populations. It is worth noting that the starting populations in 2011 for facilities that were treated the year before had considerably reduced numbers emerging from food cups compared to 2010, which may support a cumulative 
suppression of $L$. serricorne by mating disruption in the first year. Field work with stored product insects is notorious for variable data from insect populations because of the variation from building to building in sanitation, host quality and other environmental conditions (Phillips 2006), and we suspect that variation in our field populations resulted in equivocal food cup results. A better assessment method for direct sampling of reproductive changes and population dynamics in L. serricorne is needed for future mating disruption research.

This study on the high release of synthetic pheromone for mating disruption clearly demonstrated that male response to sex pheromone sources can be significantly reduced and shows good potential to be effective for mating disruption of $L$. serricorne as a pest management tool in stored products environments. Results clearly showed a significant reduction in the number of male beetles caught in traps over two seasons and in multiple buildings. Although this result is an indication of synthetic pheromone effects on male behavior, it does not necessarily signify that successful mating disruption took place. It is unfortunate that effects of changed male behavior on population-level reproduction could not be assessed from the irregular results of progeny production from oviposition cups.

Therefore, this study suggests that more research should be conducted that properly assess impacts on reproduction as it develops mating disruption techniques for effectively managing L. serricorne in stored products systems. Field studies like these with stored products are challenging because in many cases it is not possible to easily or consistently obtain direct measures of pest insect population size from commodity sampling, as one might obtain from sampling infested host material in other agricultural systems such as raw crops, vegetables or fruit trees. Future research on mating disruption in L. serricorne should utilize numerous buildings of similar size, commodity types and storage levels, and beetle population sizes for application of treatments, along with a better assessment of population dynamics from direct and indirect sampling. This report is the first to show the potential for L. serricorne mating 
disruption as a pest management alternative. The work here may also be the first reported for the potential for mating disruption of any beetle species that uses a female-produced sex pheromone (Burkholder 1970, Witzgall et al. 2010). 


\section{Acknowledgements}

We acknowledge Ms. Lemeisha Jones, Ms. Sakina Alawy, Mr. Daniel Clark and Mr. Brian Gary for assisting in the field work. We thank the National Institute of Food and Agriculture, United States Department of Agriculture, Project No. SCX-311-11-09 for the funding. The 1890 Research and Extension Program at South Carolina State University administered the grant. Additional support to TWP from the Kansas Agricultural Experiment Station is also appreciated. We are very thankful to various companies in South Carolina who allowed us access to conduct research on their property and to Trècè Incorporated for providing the mating disruption pheromone dispensers and monitoring traps. 


\section{References}

Allotey J, 1988. A study of the insect pests in stored palm produce in Port Harcourt, Nigeria. J. Stored Prod. Res. 24, 237-240.

Ashworth JR, 1993. The biology of Lasioderma serricorne. J. Stored Prod. Res. 29, 291-303.

Bry RE, Boatright RE, Lang JH, 1974. Damage to cotton textile bag sewing thread by larvae of the cigarette beetle (Coleoptera: Anobiidae). J. GA. Entomol. Society 9, 111-115.

Burkholder WE, 1970. Pheromone research with stored-product Coleoptera. In: Control of insect behavior by natural products. Ed. by Wood D, Silverstein R, Nakajima M, Academic Press, New York, NY, 1-20.

Cardé R, Minks AK, 1995. Control of moth pest by mating disruption, success and constraints. Annu. Rev. Entomol. 40, 559-585.

Chuman T, Kohno M, Kato K, 1980. A novel synthesis of ( \pm )-Serricornin4, 6dimethyl-7-hydroxy-nonan-3-one, the sex pheromone of cigarette beetle (Lasioderma serricorne F.). Agric. Biol. Chem. 44, 2259-2260.

Chuman T, Mochizuki K, Mori M, Kohno M, Kato K, Noguchi M, 1985. Lasioderma chemistry sex pheromone of cigarette beetle (Lasioderma serricorne F.). J Chem. Ecol.11, 417-434.

Dimetry NZ, Barakat AA, El-Metwally HE, Risha EME, Abd El Salam AME, 2004. Assessment of damage and losses in some medicinal plants by the cigarette beetle (Lasioderma serricorne (F.). Bull. Nat. Res. Center of Egypt 29, 325-333.

Edde PA, Eaton M, Kells SA, Phillips TW, 2012. Biology, behavior and ecology of pests in other durable commodities. In: Stored product protection. Ed. by Hagstrum DW, Phillips TW, Cuperus G, Kansas State University Press, Manhattan, KS, 45-61. 
Fardisi M, Mason LJ, 2013. Influence of lure (food/sex pheromone) on young mated cigarette beetle (Lassioderma serricorne (F.)) (Coleoptera: Anobiidae) flight initiation. J. Stored Prod. Res. 53, 15-18.

Faustini DL, 1985. Stored insect control: a biotechnical approach to cigarette beetle monitoring. Tobacco Reporter 112, 44-47.

Howe RW, 1957. A laboratory study of the cigarette beetle, Lasioderma serricorne (F.) (Col., Anobiidae) with a critical review of the literature on its biology. Bull. Entomol. Res. 48, 119-135.

Jacob S, 1992. Host food preference of the cigarette beetle, Lasioderma serricorne (F.) to few stored spices. Plant Prot. Bull. 44, 16-17.

Mahroof RM, Phillips TW, 2008a. Life history parameters of the cigarette beetle, Lasioderma serricorne (F.) as influenced by food resources. J. Stored Prod. Res. 44, 219226.

Mahroof RM, Phillips TW, 2008b. Responses of stored-product Anobiidae to pheromone lures and plant-derived volatiles. J. Appl. Entomol. 132, 161-167.

Minor MF, 1979. Do adult cigarette beetle feed? Tobacco Science 23, 61-64.

Phillips TW, Cogan PM, Fadamiro HY, 2000. Pheromones. In: Alternatives to pesticides in stored-product IPM. Ed. by Subramanyam Bh, Hagstrum DW, Kluwer Academic Publishers, Boston, MA, 273-302.

Phillips TW, 2006. The science and technology of postharvest insect control: challenges, accomplishments and future directions. In: Insect management for food storage and processing, 2nd Edition. Ed. by Heaps J, American Association of Cereal Chemists, St. Paul, MN, 211-22.

Powell TE, 1931. An ecological study of the tobacco beetle, Lasioderma serricorne Fabr., with special reference to its life history and control. Ecol. Monogr.1, 333-393. 
SAS Institute, 2003. The SAS System Version 9.3 for Windows. SAS Institute, Cary, NC.

Shorey HH, Gaston LK, Saario CK, 1967. Sex pheromones of noctuid moths. XIV. Feasibility of behavioral control by disrupting pheromone communication in cabbage loopers. J. Econ. Entomol. 60, 1541-1545.

Webb SE, Mortensen JA, 1990. Evaluation of bunch grape rootstocks and muscadine varieties for resistance to grape root borer. Proceedings of the Florida State Horticultural Society 103, 310-313.

Weihman SW, Liburd OE, 2006. Mating disruption and attract and kill as reduced risk strategies for control of grape root borer Vitacea polistiformis (Lepidoptera: Sesiidae) in Florida vineyards. Fla. Entomol. 89, 245-250.

Witzgall P, Kirsch P, Cork A, 2010. Sex pheromones and their impact on pest management. J. Chem. Ecol. 36, 80-100. 


\section{Figure Legends}

Figure 1: Mean \pm SE number of cigarette beetles captured in sticky traps in treated mills two weeks before and after mating disruption in 2010. Data were analyzed by two-way ANOVA using the GLM procedure of SAS. Tukey Groupings were used $\alpha=0.05$. There were no significant differences $(\mathrm{P}>0.05$ in each case) for beetles trapped before or after treatment for either mill.

Figure 2: Mean \pm SE number of cigarette beetles captured in sticky traps in treated mills eight weeks before and after mating disruption in 2010. Data were analyzed by two-way ANOVA using the GLM procedure of SAS. Tukey Groupings were used $\alpha=0.05$. Mean number of beetles for a given mill followed by different letters are significantly different $(\mathrm{P} \leq$ $0.05)$

Figure 3: Mean \pm SE number of cigarette beetles captured in sticky traps in treated mills two weeks before and after mating disruption in 2011. Data were analyzed by two-way ANOVA using the GLM procedure of SAS. Tukey Groupings were used $\alpha=0.05$. Mean number of beetles for a given mill followed by different letters are significantly different $(\mathrm{P} \leq 0.05)$

Figure 4: Mean \pm SE number of cigarette beetles captured in sticky traps in treated mills eight weeks before and after mating disruption in 2011. Data were analyzed by two-way ANOVA using the GLM procedure of SAS. Tukey Groupings were used $\alpha=0.05$. Mean number of beetles for a given mill followed by different letters are significantly different $(\mathrm{P} \leq$ $0.05)$

Figure 5: Mean \pm SE number of cigarette beetles captured in sticky traps in Warehouse two and eight weeks before and after mating disruption in 2011. Data were analyzed by independent t-tests (PROC T-TEST) at $\alpha=0.05$ level using SAS. Mean number of beetles for a given week followed by different letters are significantly different $(\mathrm{P} \leq 0.05)$ 
Fig. 1

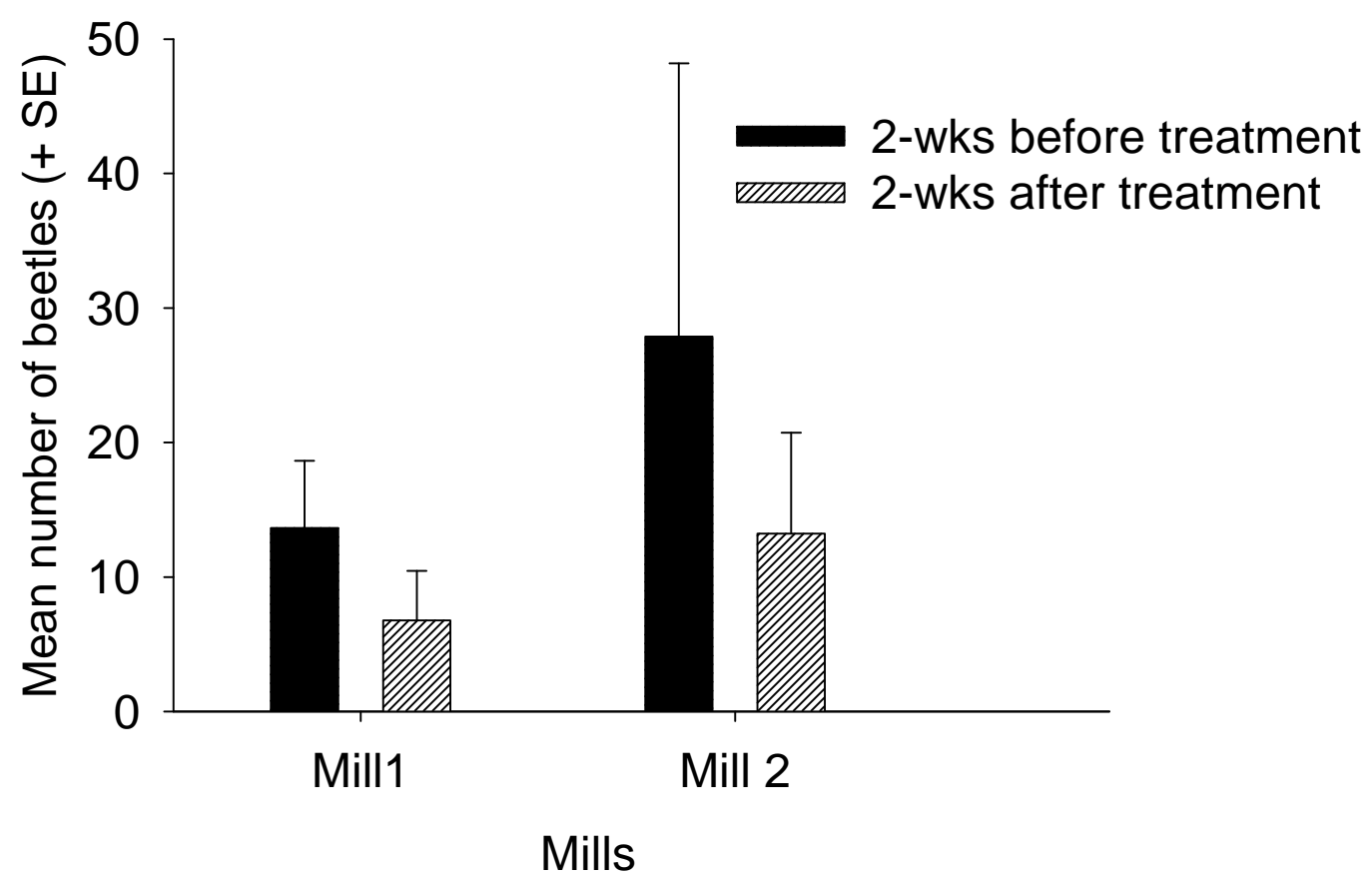


Fig. 2

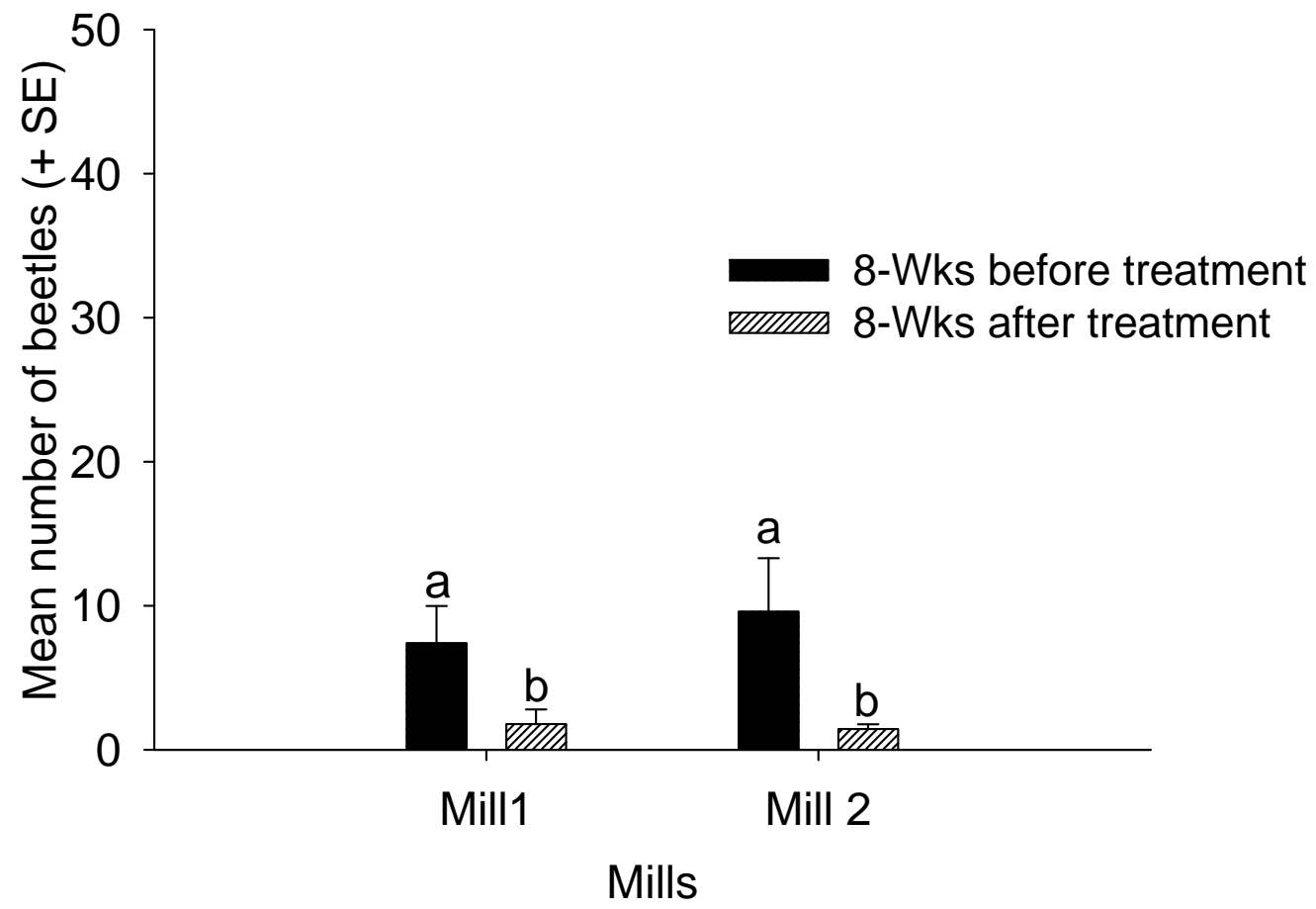


Fig. 3

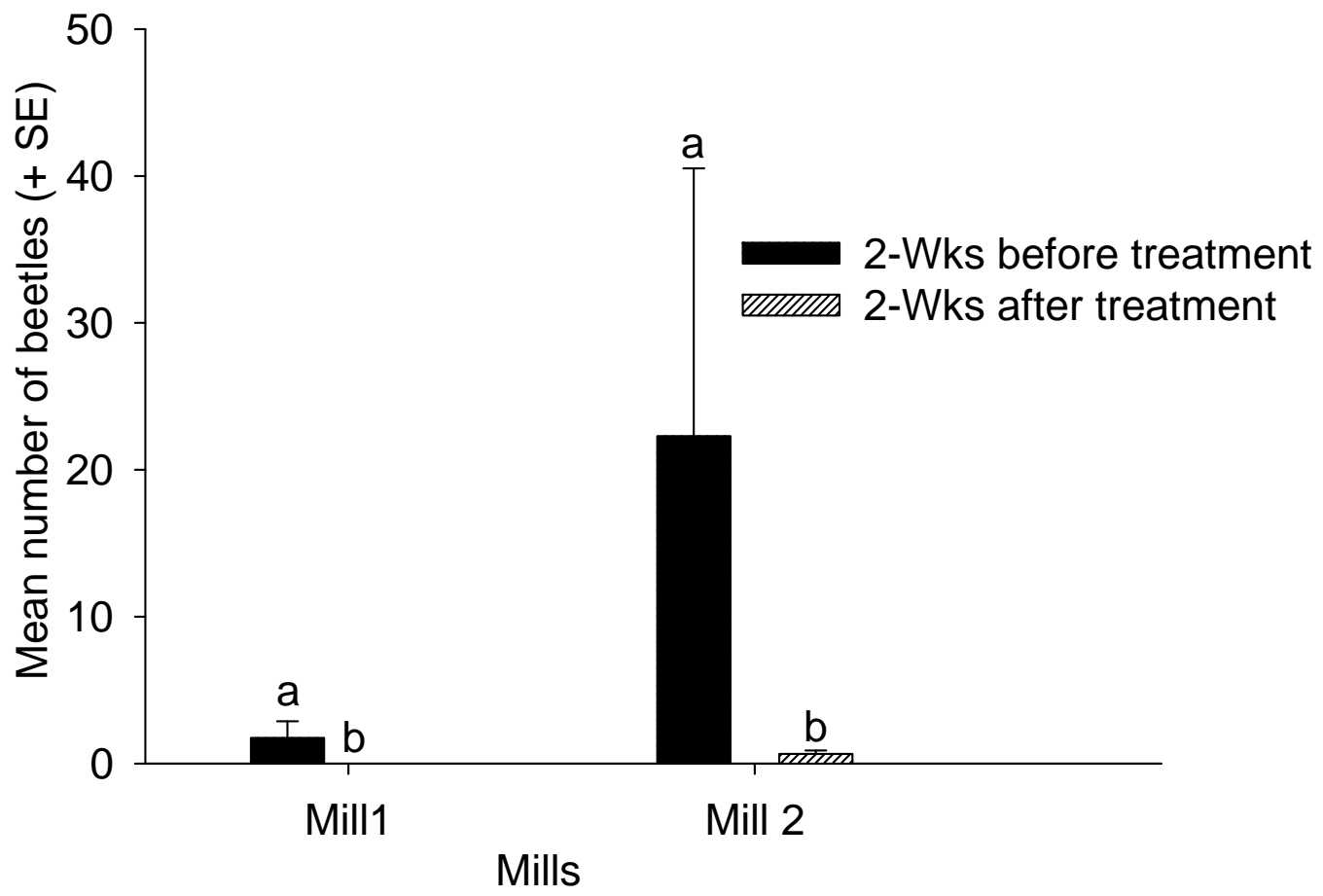

24 
Fig. 4

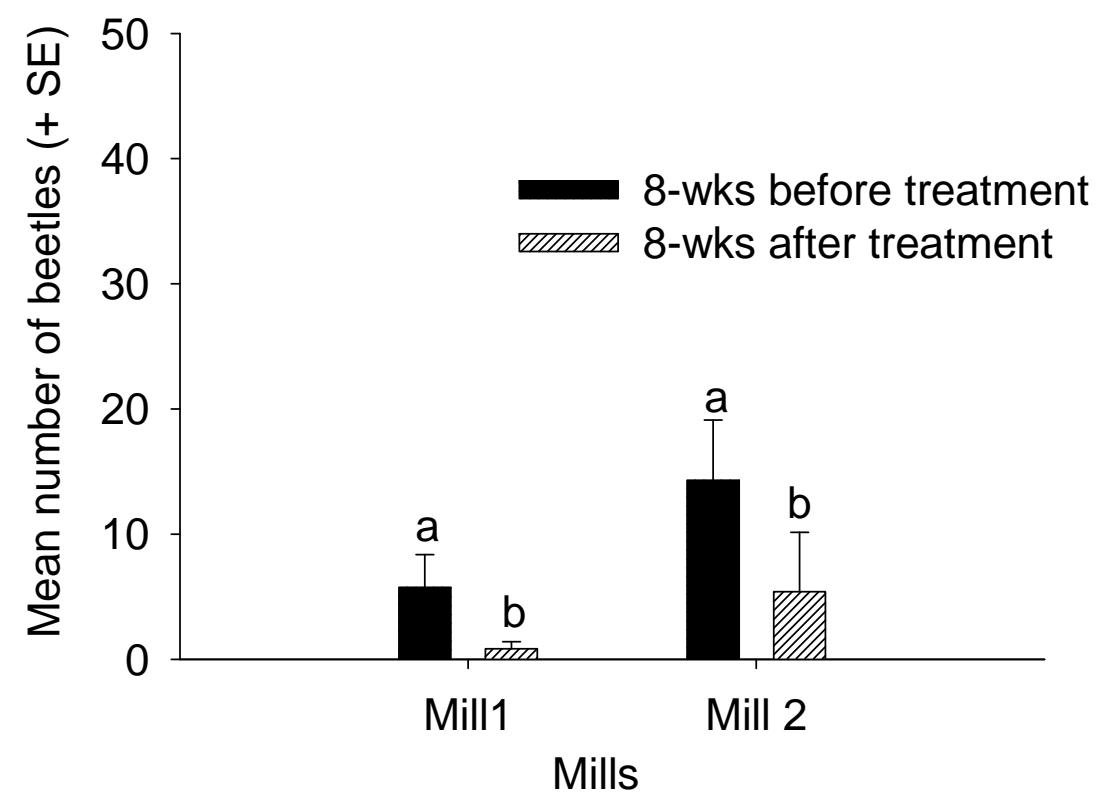


Fig. 5

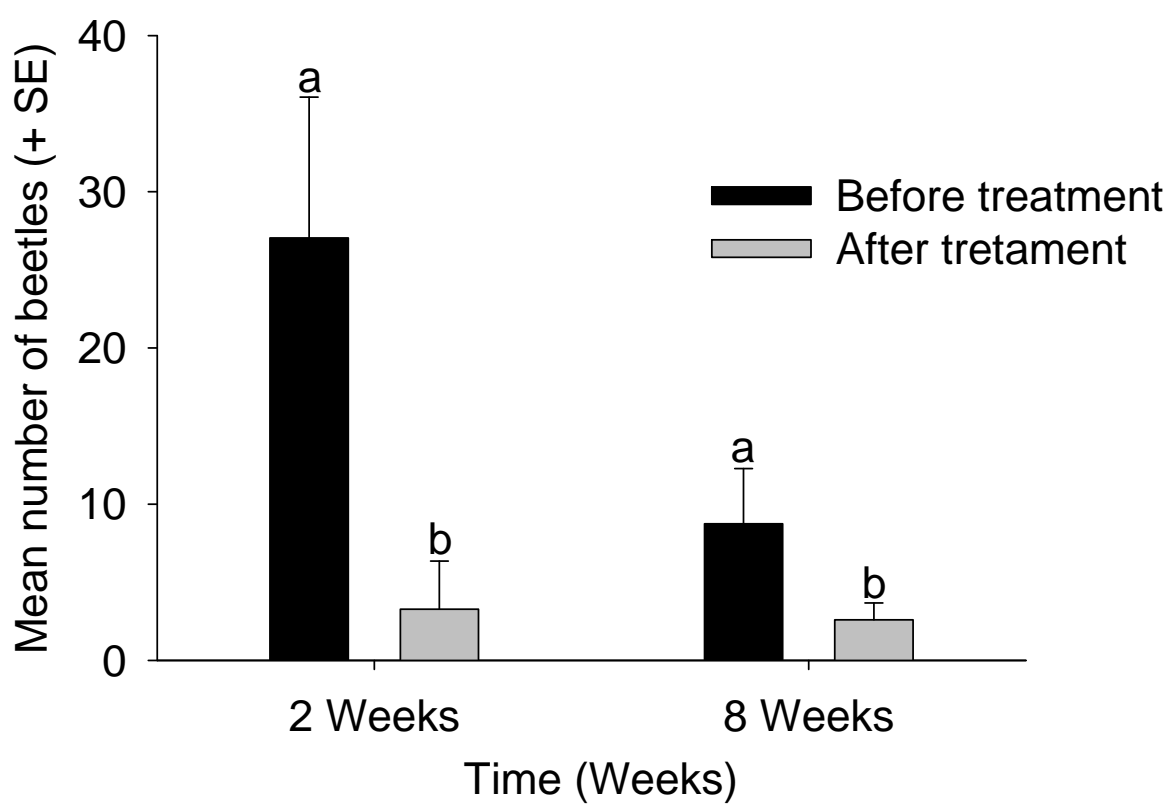

